\title{
Responsible research and innovation: Promoting a scientific career among young people
}

\author{
Marta Majorek $^{1 \mathrm{a}}$, and Justyna Wojniak ${ }^{2}$ \\ ${ }^{1}$ Andrzej Frycz Modrzewski Krakow University, ul. Herlinga-Grudzińskiego1, 30-705 Krakow, \\ Poland \\ ${ }^{2}$ Pedagogical University of Krakow, ul. Podchorążych 2, 30-084 Krakow, Poland
}

\begin{abstract}
Responsible Research and Innovation is a project initiated by the European Commission in 2014, involving 26 institutions from 30 European countries. Its main purpose is to create science and innovation with society and for society by developing harmonious relations between science and society in Europe. One of the most important dimensions of responsible research and innovation is to make young people aware of scientific specificities of the different aspects of social life and the relationship between science and society. The next step would be encouraging them to choose science as a future path of their career. Therefore it raises the question of the extent to which modern educational systems, not only in Poland, are ready for this kind of challenge. In education strategies or reform projects these issues are firmly underlined. It remains however doubtful whether these are not just idle declarations devoid of real dimension. The paper presents leading European project IRRESISTIBLE aimed at promoting science among young people and making them interested in scientific career. This will be confronted with the Polish young people's views on science education and their attitude towards scientific career.
\end{abstract}

Keywords: Scientific career; young people; irresistible

\section{Introduction}

One of the main reasons for emergence of Responsible Research and Innovation emergence was the unsatisfactory contribution of scientific institutions in economic development, solving the contemporary world's problems, developing solutions intended to get rid of economic barriers and technological limitations that restrain the contemporary economy. More active contribution of the sad institutions was assumed to improve life quality. Examples of effective involvement of the scientific environment in solving the above-

\footnotetext{
${ }^{a}$ Corresponding author: marta@majorek.com
} 
mentioned issues show the scope of possibilities in that range. However, political decisionmakers and publicity are dissatisfied with improper use of this potential. This gives further possibilities of actions and encourages to develop priorities in terms of scientific practice and remove barriers in cooperation of the scientific environment and other social actors.

\section{RRI concept - its origins and development}

It seems necessary here to answer a question on what the above-mentioned Responsible Research and Innovation concept - abbreviated to RRI - are. The first definition was developed by Rene Von Schomberg in 2011 who assumes that we should understand it as: "a transparent, interactive process by which societal actors and innovators become mutually responsive to each other with a view on the (ethical) acceptability, sustainability and societal desirability of the innovation process and its marketable products (in order to allow a proper embedding of scientific and technological advances in our society)" [1].

A common feature of all initiatives carried out under the auspices of Responsible Research and Innovation is active development of the future. These actions consist in solving so-called complicated problems what requires plenty of data to be collected and new algorithms for their analysis to be developed for the need of decision making and social contribution to scientific research. Hence, there must be actions undertaken intended to identify the methods that ensure efficient cooperation with local communities and openness towards diversified recipients.

The European Commission's opinion is that development of scientific activity should go hand in hand with researchers' social responsibility, but at the same time with the society's awareness. To achieve such a state of affairs it becomes indispensable for the scientific and social spheres to cooperate. This requires a dialog between representatives of both those environments occupying equal positions. Keeping a high level of the scientific research and technological innovation requires continuous recruitment of talented researchers, but also inspiration. The researchers come from a broadly understood society, and the impulse for development of research problems is posed by social needs and expectations. However, it must be kept in minds that the scientific environment should restrain from treating publicity in a paternalistic manner and perceiving it as a poor recipient of scientific activity's results. Thus, the element of social control over such activity gains on importance, i.e. legal and ethical aspects of its performance as well as the mentioned social needs and expectations, grasped in the system of values context, significant from the perspective of the society as a whole. Such an approach is related to particular democratization of the science development process. It is worth adding that democratization perceived in such a manner has its relatively practical justification, arising from the fact that financing of the scientific and research operations comes from public resources.

"The ultimate goal is bring into being a European community of practice that draws together all people and organisations that are active in this new vision of scientific and social development" [2].

The European Commission, to achieve the goal in cooperation with multiple entities representing scientific, economic and social sectors, has developed a project named RRI Toolkit. It covers concepts and examples of good practices in several major spheres. One of them is sex equality, i.e. exclusion of all premises of discrimination based on sex, when it comes to access to possibilities, resources or advantages provided thanks to the science sector development [3]. This perspective provides special importance to the possibility of revealing the full societal potential, which can be thus employed for developmental purposes. Apart from that, RRI Toolkit also covers the already mentioned social contribution into the process of research and innovation development, which is seen 
through participation of scientists, industry and representatives of the civic environment. Another area is facilitating access to research results what is especially important in case of research financed from public funds. Following ethical standards in the process of research development and innovative solutions implementation is attached with the same importance. In this case, a fundamental reference point is social significance and acceptability of the obtained results. There is also a need to mention management in the scientific and research sector, which is to be characterized with responsibility of decisionmakers for development of harmonious RRI models [4]. Eventually, there is an educational area mentioned, both in its formal and informal form, construed in such a manner so it poses a path of promoting a scientific career among young people as a potential path of the future professional development [5].

These are the elements that compose the core of assumptions, which were highlighted as crucial within the Horizon 2020 programme. Therefore, it is obvious that in order to allow effective introduction of those assumptions, it is necessary to grant the operations intended for their implementation. Nevertheless, the whole process will bring expected results only if financing plans for particular RRI actions were given some thought. It was assumed on one hand that there is a need to distinguish a group of funds intended for implementation of RRI projects within the already existing programmes realized by European Union member states, especially those, which assume financing of the scientific and research operations. The existing programmes were provided with catalogs of rules that should be followed while assigning funds for research [6]. These actions were intended to improve awareness about RRI in an indirect manner, although introduction of such solutions into the already existing programmes seems insufficient. Hence, a decision was made to undertake more direct actions, which would cover particular funding instruments with a purpose to implement particular projects meeting the RRI criteria [7].

An example of direct actions may be Joint Programming Initiatives, which is intended to direct resources of particular states, allocated solely to implementation of innovative research, which would pose a response to the challenges that contemporary societies must face. A decision was made to develop a pilot phase of the project as a reaction to small recognizability of the RRI concept in particular member states. This phase adopts a form of dedicated financial instruments included in the Horizon 2020 programme. An example of direct support for RRI implementation is also the European Innovation Partnership, intended to focus on support for improvement in European competitiveness. The concept assumes introduction of a strategic approach for development and implementation of innovation what is rooted in the European Union strategy for 2020. According to those assumptions, RRI is to become its integral part [8]. It is assumed that introduction of the RRI concept will allow realization of undertakings both on a local and supralocal scale through implementation of new technological solutions.

When it comes to possibilities brought by technologies to the area of solving contemporary problems, attention is focused on the need to improve social awareness in that scope. This is also related to recognition of potential threats and risks that can be noticed here. Thus, it is impossible to bring notions related to science and technology closer to publicity without adequate preparation of the recipients. Therefore, education, both in the formal and informal manner plays a crucial role here. On one hand, it provides individuals with the most elementary knowledge on phenomena or processes that pose the research subject in an obvious manner. On the other hand - its role should be to trigger interest in that area and achievement that emerge within it. However, it is equally important to shape some critical attitudes during the educational process, directed to some forms of scientific operations or its potential effects. 


\section{RRI in education}

In the educational area, RRI means not only the change in the manner young people perceive innovative technologies and their use, but also encouragement for participation in scientific projects [9]. Hence, actors involved in RRI Toolkit development felt it was appropriate to get young people acquainted with specificity of the scientific profession. This is justified because a lot of stereotypes arose around it, among which the most popular is the belief about its tightness and inaccessibility for an average recipient. On the other hand, bringing the scientific profession closer to young people is a condition necessary to make them interested enough in that sphere so the gifted and talented students can locate their professional future in that sector.

Undoubtedly, this though may be improved by initiatives and activities carried out on all educational levels, especially in primary and lower secondary schools, where young people will not only obtain knowledge in sciences, but also get familiar with possibilities and consequences of a research process. Shaping of attitudes that are open to challenges that are brought by scientific work is another step for development of the society of knowledge, and triggering the individuals' willingness for direct participation in the innovation process.
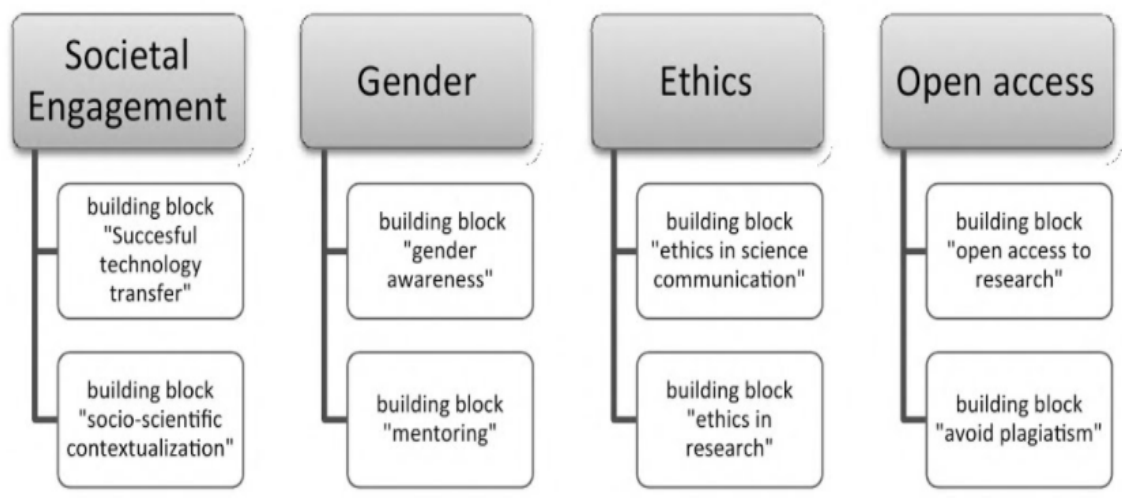

Fig. 1. Key-specific building blocks that form the educational RRI training program (source: [6])

From the educational perspective, especially in its formalized dimensions, one of the most interesting initiatives that implement the RRI assumptions seems the IRRESISTIBLE project (Including Responsible Research and Innovation in Cutting Edge Science and Inquiry-Based Science Education to Improve Teacher's Ability of Bridging Learning Environments). It combines the elements of formal and informal education, directed towards responsible research and innovation.

In Poland, the project was implemented within the scope of actions coordinating and supporting the FP7-SCIENCE-IN-SOCIETY-2013-1 Activity 5.2.2 entitled Young people and science. Topic Sis.2013.2.2.1-1. Improvement of young people's awareness in terms of responsible research and innovation through education in the scope of sciences and scientific inquiry. In this scope, the aim of IRRESISTIBLE has become to develop actions intended to support involvement of students and society into the process of responsible research and innovation [10].

In the context in question it is worth paying attention especially to one of the abovementioned elements, namely on education in the scope of sciences. There are not many European states that have developed particular strategies intended to improve the position 
of sciences in education and within the society. However, it does not mean that states do not implement initiatives aimed at improvement in educational quality in the STEM system. It is hard to measure the impact of those unitary activities, thus the need for in-depth research in that scope, allowing to review and assess the undertaken initiatives. Strategies popular in Europe assume cooperation between schools and scientific organizations, while the areas of partnership are highly differentiated what is reflected also in different manner of organization and implementation of such practices.

At least one of the following objectives is embedded in all kinds of partnerships: promotion of sciences, knowledge and research among students; improvement in students' understanding of practical use of science; improvement of didactics of sciences in schools, and improvement of recruitment for mathematic, scientific and technical majors. Scientific centres assume at least one of the above-mentioned goals, and make their contribution into improvement in teaching of sciences through implementation of student-oriented actions, which go beyond the schools' offer. Two thirds of interviewed states inform that there are no scientific centres on the national level. Wherever general strategies for promotion of sciences are prepared, their integral part is usually the student-oriented counseling. However, there are not many states that introduced counseling practices that would especially consider sciences, and only in few were the girls encouraged to choose such a professional career. There are few states, where programmes and projects intended to provide special support for students that are gifted and have talent for science were introduced [11]. The mentioned facts justify promotion of postulates put forward within the RRI, and point to the need for improvement in awareness of that concept and strengthening promotion of scientific development directions included in STEM.

Within the discussed project IRRESITIBLE, awareness of RRI was developed in two manners:

- improvement of scientific research knowledge by introducing latest achievements into the curricula for sciences, encouraging and supporting discussions about RRI among students;

- formal (in schools) and informal (in science centres, museums, during scientific festivals) education; students learn about the world of science.

Each state that declared its participation in the project created Community of Learners $(\mathrm{CoL})$, the task of which was to develop didactic modules. Those teams were composed not only of teachers but also of university lecturers and designers of interactive exhibitions. The Community of Learners develops materials intended for work with students. Furthermore, students of the teachers involved in CoL visited university laboratories, and based on that they prepared exhibitions that pictured the relationship between scientific research and the society [12].

Implementation of the project was divided into two main stages. 1st stage of the project resulted in 10 modules about various types of RRI, tested in 5-10 classes.

Topics of the modules:

- Healthy aging

- Genomics and oceanography

- Climate change

- Sustainable renewable energy

- Solar energy

- Nanomaterials

- Nanotechnology

- Catalysis in protection of the environment

During the 2nd stage of the project, 7 teachers that took part in the 1st stage had the task to train other five persons. The modules are also available on a special website available in various languages. The best exhibits developed within the project were 
presented to the public during the project completion ceremony. As a result, within the project, almost 10 thousand students were sensitized to social effects of scientific research.

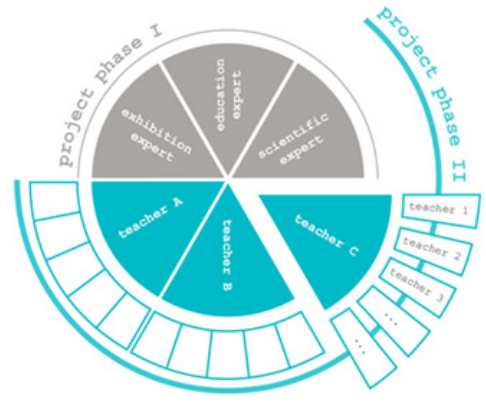

Fig. 2. Project approach (source: [10])

RRI Toolkit assumptions, which were planned for implementation in the education areas and the actions undertaken in that scope based on an example of a particular initiative in a form of the project IRRESISTIBLE provided the authors of this article with a field for analysis of the young people's attitude towards sciences as an object of education and as a sphere of social and professional activity. The performed research also allowed to attempt to evaluate the implemented solutions related to promotion of responsibility in the research and innovation operations, according to assumptions adopted by the European Commission.

\section{Procedure and findings}

The research was carried out in 2017 on 16-year-old students of 3rd grade of a lower secondary school, finishing their education on that level. Selection of a sample group was of a purposeful character not only because of the possibility to reach the respondents. From the perspective of the analyzed problem, it was also significant to cover a particular group with the research, namely the students, who took part in the discussed project IRRESISTIBLE.

The research was carried out with the diagnostic survey method, adopting a tool in a form of a survey questionnaire. The survey was of an anonymous character. The answers were collected from 69 persons, out of which 21 were students of a school where the project IRRESISTIBLE was carried out.

Questions included in the questionnaire were intended to identify how the students perceived science education. Majority $(60 \%)$ of respondents from the group that did not take part in the project IRRESISTIBLE responded that this was a difficult sector. The students who had a chance to get familiar with the scientific notions in a broader scope thanks to their participation in the said project, the proportions were opposite, as $62 \%$ of respondents claimed that science education is a tough field. Such a scheme of answers may result from deeper and broader description of the scientific notions to students from the group IRRESISTIBLE. In their case, not only classic expository methods were employed as it happens in case of the obligatory educational process, where often - regarding time limitations - realization of core curriculum is focused on theoretical aspects, not always accompanied by illustration in a form of an experiment or practice.

Afterwards, the students were asked to determine the degree of science education knowledge usability in comparison to other subject, among others social sciences. Here, in the group of students not covered by the project IRRESISTIBLE, 25\% of respondents claimed it was more useful, $58 \%$ said it was useful to the same degree, and $17 \%$ pointed it 
was less useful. In turn, it was surprising in the group IRRESISTIBLE that only 5\% believes science education is more useful, while as many as $81 \%$ pointed that it was useful to the same degree. The group stating that science education is less useful was $14 \%$. This may lead to a conclusion that students, who had a chance to participate in the project bringing the sphere of science closer believed that such activity should not be attached with features that would distinguish it from other spheres of a human intellectual activity. It might be related to being aware that social life along with individual needs and expectations require differentiated strategies for solving specific problems and undertaking challenges that are adequate for a given situation. Therefore, science and solutions it offers may be one of numerous proposals that should be used in a flexible manner, without the desire to treat it with superiority.

The opinion that understanding science education and moving freely within its notions exerts positive influence on individual career possibilities was expressed by $65 \%$ of students from the group non-IRRESISTIBLE, when compared to $52 \%$ from the group IRRESISTIBLE.

Quite interesting results were also provided by answers to the question about an image of a researcher that dominates within the minds of young people, without dividing them into non-IRRESISTIBLE and IRRESISTIBLE groups. The respondents could select 3 positions out of the proposed answers: Creative (A), Extremely intelligent (B), With passion (C), Detached from the reality (D), Bookworm (E) and Enterprising (F).

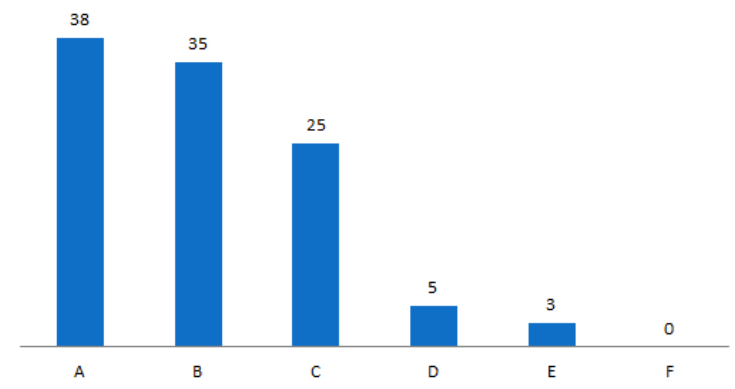

Fig. 3. Image of the researcher

As it may be noticed, the dominating features are those that can be thought of as positive in case of a researcher's image. Definite minority pointed here to features associated with researchers stereotypically or ironically, i.e. detached from reality or remaining in the world of books and scientific papers. None of the students pointed to enterprising what may suggest that scientific practice is still associated with a sort of a mission, actions for common good, not gaining profits. Such a belief should grow some thought for decision-makers, both on the European and national level, who definitely stress the significance of the link between science and innovation within various developmental strategies, along with the need for deep commercialization of scientific research results.

Further, the students were asked about attractiveness of the scientific profession. The following were proposed as its determinants: Contribution to the human development (A), Fascinating (B), Financially attractive (C), Boring (D), Financially unattractive (E), Harmful to people and environment (F). 


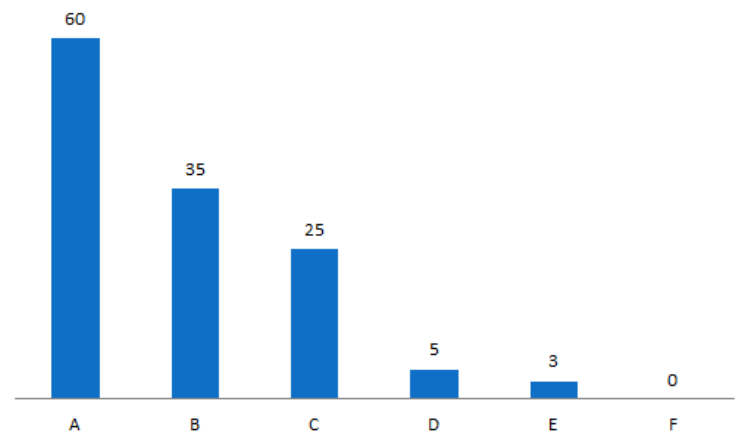

Figure 4. Attractiveness of the scientific profession

Here also the positive aspects dominate, with a definite belief in its role from the perspective of contribution to humanity development. What may be surprising is the fact that the respondents did not even think about the risk element that the scientific and innovative activities' results may bring to people or environment. This may prove limited level of criticism and scale of imagination what is surprising as the popular culture, first of all the movie, delivers a lot of examples of dangerous activities of "mad" scientists. Such a positive attitude towards a social role of a researcher may be also linked to the question asked previously, for which the students provided the answer suggesting that their minds have strongly adopted a belief that scientific practice has no premises of enterprising, so it should be combined with the previously mentioned mission for realization of the common good.

What is more, a relatively large group thought of a scientific profession as financially attractive, thus providing a certain scope of life stability what according to the respondents probably does not support risky or ethically doubtful behaviors that would result in negative impact on the researcher's life situation.

At the end, it is worth mentioning answers for the question on whether the respondents have any professional plans related to science. The results were identical in both researched groups:

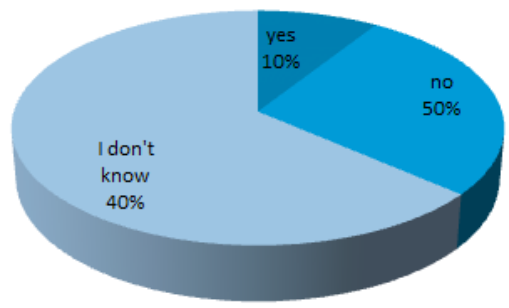

Figure 3. Professional plans related to science

Most probably, the small share of affirmative answers results from limited awareness of what the profession is connected with, and what the duties of a researcher are. Undoubtedly, it is not a job that - in colloquial meaning - is related to a particular sector or position. Knowledge about remuneration or employee entitlements is also strongly limited. On the other hand, a justification for as many as $40 \%$ of those undecided may be the fact that a 16-year-old individual is not yet old enough to make more particular decisions on 
their professional future. On this stage, young people tend to focus on choosing an upper secondary school, and from their perspective it might be too early, to already decide on the major in academic or direction in vocational education.

\section{Conclusion}

To sum up the results it must be added that schools as institutions, also the employed staff, do not prove their understanding of the Responsible Research and Innovation. Reports compiled by the European Commission, as a body responsible for all community initiatives related to education and courses suggest that a condition for implementation of the RRI Toolkit's assumptions in all areas mentioned by the Commission is modernizing science initial teacher training programmes, particularly by updating of initial teacher training courses, as well as establishment of national quality standards for science initial teacher education - 49 students as a reason for the lack of interest in the field of science mentioned a poor teacher. There is also a need to update the skills of in-service teachers to motivate learners, which demands the development of new dedicated degree programmes and close cooperation between schools and universities [13].

\section{References}

1. R. von Schomberg, Prospects for Technology Assessment in a framework of responsible research and innovation, in: Technikfolgen abschätzen lehren: Bildungspotenziale transdisziplinärer Methode, Springer VS, Wiesbaden, 39-61 (2011)

2. European Commission, RRI Tools: building a better relationship between science and society, retrieved: http://www.rri-tools.eu/project-description (2014)

3. Ibid.

4. Z. Gontar, Odpowiedzialne badania i innowacje - nowy paradygmat $w$ budowaniu wspólpracy między nauka i społeczeństwem, Collegium of Economic Analysis Annals, 40, 325 (2016)

5. G. A. Anghel, G. Gorghiu, Considering Responsible Research and Innovation in Science Education Teaching Approaches at Primary Level, International Journal of Teaching and Education, 5 (1), 9 (2017)

6. D. Elster, T. Barendziak, J. Birkholz, Science Education as a Trigger to Attain Responsible Research and Innovation (RRI) in Biosciences, in: Conference Proceedings. New Perspectives in Science Education, 402 (2017)

7. European Commision, Options for Strengthening Responsible Research and Innovation Report of the Expert Group on the State of Art in Europe on Responsible Research and Innovation, retrieved: https://ec.europa.eu/research/sciencesociety/document_library/pdf_06/options-for-strengthening_en.pdf, 32. (2013)

8. Ibid.

9. J. Apotheker, R. Blonder, S. Akaygun, P. Reis, L. Kampschulte, A. Laherto, Responsible Research and Innovation in secondary school science classrooms: experiences from the project Irresistible, Pure and Applied Chemistry, 89, 2, pp. 211219 (2016)

10. IRRESISTIBLE, Project Approach, retrieved: http://www.irresistibleproject.eu/index.php/en/approach (2017)

11. European Commision - Eurydice, Nauczanie przedmiotów ścistych i przyrodniczych w Europie: polityka, praktyka i badania naukowe, 
retrieved:

http://eacea.ec.europa.eu/education/eurydice/documents/thematic_reports/133PL.pdf, 9 (2012)

12. Jagiellonian University - Programme Irresistible, retrieved: http://www.zdch.uj.edu.pl/irresistible (2017)

13. European Commission Indicators for promoting and monitoring Responsible Research and Innovation Report from the Expert Group on Policy Indicators for Responsible Research and Innovation, Publications Office of the European Union, Luxembourg, 41-43 (2015) 